\title{
Costello Syndrome with Congenital Pulmonary Valve Stenosis and Ventriculomegaly-A Case Report
}

\author{
Ramachandran Muthiah \\ Thoothukudi Medical College Hospital, Thoothukudi, India \\ Email: cardioramachandran@yahoo.co.uk
}

Received 20 June 2016; accepted 27 August 2016; published 30 August 2016

Copyright (C) 2016 by author and Scientific Research Publishing Inc.

This work is licensed under the Creative Commons Attribution International License (CC BY). http://creativecommons.org/licenses/by/4.0/

(c) (i) Open Access

\begin{abstract}
Costello syndrome is an extremely rare genetic disorder with growth delay after birth and typically results in short stature during childhood. It is one of the RASopathy of Ras/MAPK pathway syndromes. It affects the transforming protein $\mathbf{p}^{21}$, an enzyme that in humans is encoded by the HRAS gene. H-Ras is a small G protein and once bound to Guanosine triphosphate, it will activate a Raf kinase like C-Raf, the next step in the MAPK/ERK pathway (mitogen-actvated protein kinase/ extracellular signal-regulated kinase) i.e., MEK (mitogen-actvated ERK kinase), a protein that phosphorylate ERK which can directly and indirectly activate many transcription factors. This pathway is also known as Ras-Raf, MEK-ERK pathway, which is a chain of proteins on the cell that communicate a signal from a receptor on the surface of the cell to the DNA in the nucleus of the cell. Activation of ERK 1/2 is involved in signal transduction pathways associated with cardiac hypertrophy. The developmental syndromes caused by germline mutations in genes that alter the RAS components of the MAP/ERK signal transduction pathway are called "RASopathies". Cardiovascular abnormalities are important features of Costello syndrome and other RASopathies such as Noonan syndrome. Background of this case report described the congenital valvular pulmonic stenosis and ventriculomegaly associated with Costello syndrome by transthoracic echocardiographic imaging in a 9-year-old male boy.
\end{abstract}

\section{Keywords}

Costello Syndrome, Rasopathy, Short Stature, Congenital Valvular Pulmonic Stenosis, Ventriculomegaly

\section{Introduction}

Costello syndrome is a rare genetic disorder, characterized by distinctive facial features, short stature, flexible 
joints, loose folds of extra skin and structural malformations of the heart present at birth such as valvular pulmonic stenosis and abnormal thickening of the muscular walls of the ventricles (ventriculomegaly). It was discovered by Dr. Jack Costello, a New Zealand paediatrician in 1977 [1]. Costello syndrome is inherited as an autosomal dominant genetic condition due to mutations in the HRAS gene which results in production of H-Ras protein that leads to continuous cell growth and division, causing ventriculomegaly. HRAS is a proto-oncogene and the affected individuals have an approximately 15\% lifetime risk to develop tumors such as papillomas, rhabdomyosarcoma, neuroblastoma, transitional cell carcinoma of bladder and hurthle cell carcinoma of thyroid (a follicular carcinoma, oxyphil type). These genetic mutations in HRAS causing Costello syndrome were first reported in 2005 [2] and 200 to 350 cases were reported worldwide.

Isolated pulmonic valve stenosis with dome-shaped pulmonic valve was described in 1761 by John Baptist Morgagni [3]. It occurs with an incidence of 1.5 - 6.5 per 10,000 live births, accounting for $2 \%$ to $13 \%$ of all congenital heart lesions [4]. In patients with isolated congenital pulmonic valve stenosis (no other valves or congenital cardiac condition), congenital malformations of the valve are two types; dome-shaped acommissural and dysplastic. Acommissuralstenotic pulmonic valve is usually a dome-shaped structure with a central aperture and ridges are visible that mark sites of apparently malformed commissures [5]. In dysplastic pulmonic stenosis, the pulmonic valve is a tricuspid structure and all three cusps are greatly thickened, rubbery and composed of disorganized myxomatous tissue and no commissural fusion but the valve annulus is small and pulmonary trunk is not dilated. Gikonyo and colleagues [6] found that all congenital forms had thickened cusps with or without commissural fusion. Altrichter [7] reported that $58 \%$ of stenotic pulmonic valves were bicuspid in 65 patients with Tetralogy of Fallot. The quadricuspid state of the pulmonic valve is seen in 1 in 10,000 cases at necropsy series and the frequency of dysfunctional quadricuspid pulmonic valves range from $4 \%$ to $6 \%$ [8].

The incidence of isolated congenital pulmonic valve stenosis is uncommon in Costello syndrome and so this case has been reported.

\section{Case Report}

A 9-year-old male boy was referred from the school with a history of growth retardation from childhood for evaluation. He was asymptomatic and no history of cyanosis at birth. His school performance in studies was not affected compared to other students. His pulse rate was $80 \mathrm{bpm}$ and blood pressure 110/80 mmHg. General examination revealed short stature, low-set ears, prominent head, skin folding below the lower eyelids, teeth abnormalities and skeletal changes such as mild ulnar deviation of elbows and hands, kyphoscoliosis, shortening of arms and thighs, tight tendoachilles and plantar hyperkeratosis, which are consistent with features of Costello syndrome as shown in Figures 1-4. Physical examination revealed grade 3/6 systolic murmur over the precordium, most prominent in left $2^{\text {nd }}$ intercostal space. The second heart sound was inaudible. No phasic ejection clicks due to merging of it with $1^{\text {st }}$ heart sound in severe stenosis, Jugular venous pulsation was not present and no parasternal heave. Blood chemistry revealed normal (Haemoglobin-13.7 gm\% (normal-12 to 16 g/dl), total count -9000 cells (normal—4 to 11,000 cells) per cubic mm of blood, Differential count-polymorphs—60\% (normal-40\% to $70 \%$ ), lymphocytes-30\% (normal-20\% to $40 \%$ ), eosinophils-4\% (normal-1\% to $4 \%$ ), Erythrocyte sedimentation rate-2 to $4 \mathrm{~mm} /$ hour (normal -0 to $9 \mathrm{~mm} /$ hour) and platelets-2.56 lakhs (normal-2.5 to 5 lakhs) per cubic mm of blood, ASO (anti-sreptolysin O) titer was negative ( $<200 \mathrm{IU} / \mathrm{ml})$. ECG revealed right ventricular strain pattern as shown in Figure 5. The maximum height of $R$ wave in $V_{1}$ is $14 \mathrm{~mm}$ (5 mm standardization in ECG) which corresponds to right ventricular systolic pressure of $70 \mathrm{mmHg}(14 \times 5=$ $70 \mathrm{mmHg}$ ) and deep $\mathrm{S}$ in $\mathrm{V}_{6}$. X-ray chest revealed prominent main pulmonary artery segment resulting from poststenotic dilatation of the pulmonary trunk and right ventricular hypertrophy as shown in Figure 6.

Transthoracic Echocardiographic images in Figures 7-21 given below revealed thickened, calcified, pulmonary valve with commissural fusion, severe pulmonary valve stenosis with poststenotic dilatation, suprasystemic ventricular systolic pressures and ventriculomegaly.

These features are consistent with isolated congenital valvular pulmonic stenosis and ventriculomegaly in Costello syndrome and the child was advised periodic follow-up. Screening of family members revealed normal.

\section{Discussion}

\subsection{Etiopathogenesis}

Costello syndrome is caused by any of at least 5 -different heterogenous germline mutations in the proto-onco- 


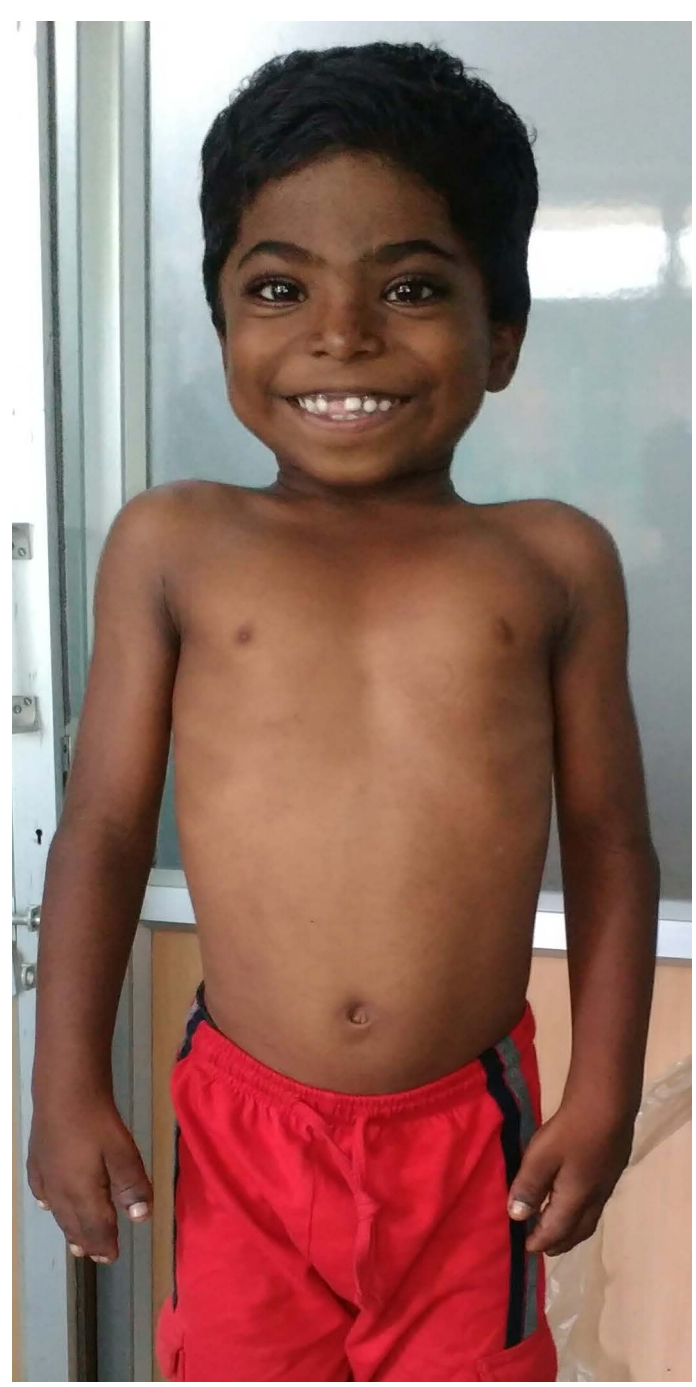

Figure 1. Showing warm, sociable personality and skin folding below the lower eyelids of costello syndrome). Photo image taken with consent.

gene HRAS on chromosome 11, involved in controlling cell growth and division on multiple organ system These mutations produce H-Ras protein which is permanently active and this overactive protein direct cells to grow and divide constantly leading to overgrowth of heart muscle (hypertrophic cardiomyopathy) as shown in Figure 8. Infants with Costello syndrome may be large at birth, but grow more slowly than the other children. Later in life, this condition has relatively short stature as shown in Figure 2 and many have reduced levels of growth hormone and it is a "RASopathy", also called as "Faciocutaneoskeletal syndrome" (FCS syndrome). In some cases, the symptoms and findings of Costello syndrome overlap with two similar disorders known as Noonan syndrome, Cardio faciocutaneous syndrome which are caused by mutations in different genes and characterized by webbing of neck, drooping of upper eyelids (ptosis) and mostly associated with dysplastic pulmonic valve.

The exact embryologic process resulting in pulmonic valve stenosis is not well understood. Maldevelopment of the distal part of the bulbous cordis has been proposed [9], but it appears unlikely that fusion of well-formed pulmonic valve cusps would occur during mid-to late intrauterine development after the ventricular septum has been completed [10]. Fused cusps of varying thickness and rigidity form a fibrous dome in the severest form and contribute the most common form of isolated valvular pulmonic stenosis. Fetal endocarditis has been proposed as a cause but not proven [11]. Maternal rubella infection may be associated with stenosis of the pulmonary artery and its branches. Genetic factors also play a role. 


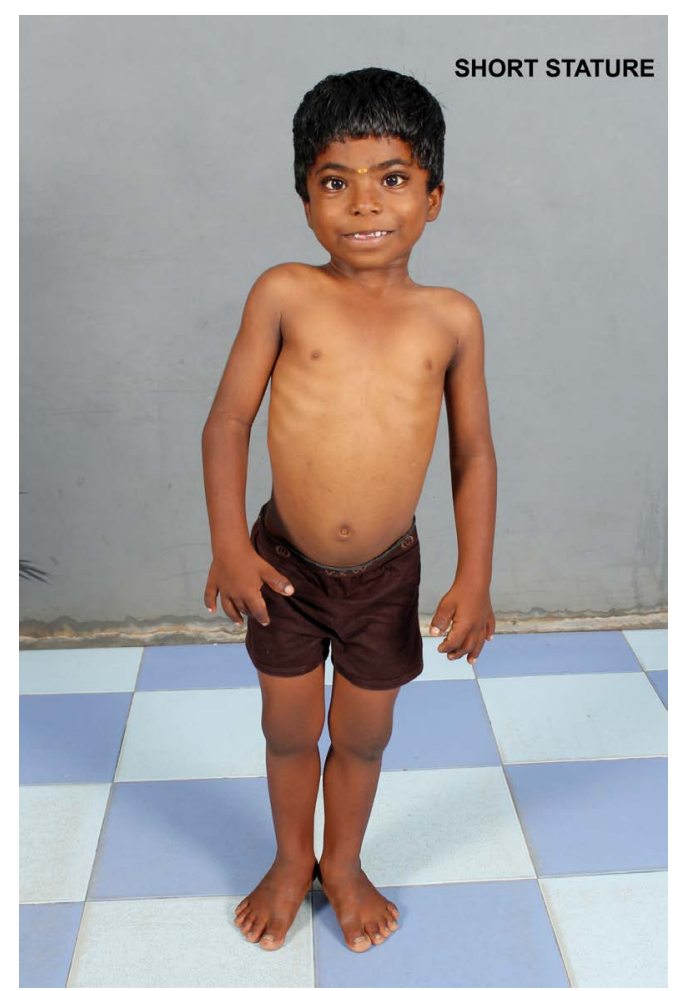

Figure 2. Showing short stature. Photo image taken with consent.

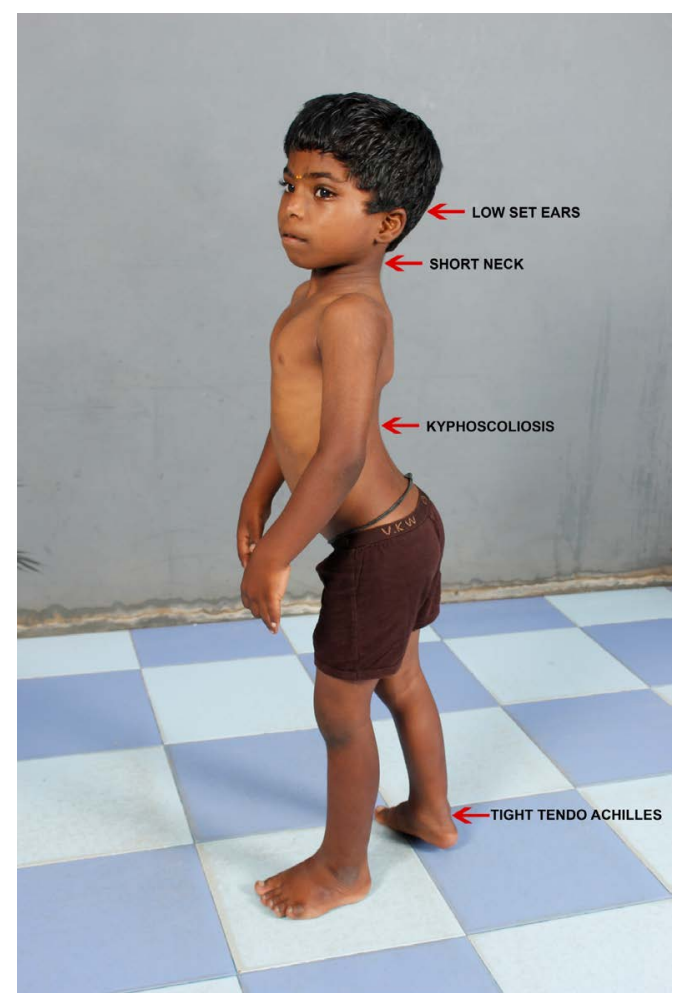

Figure 3. Showing low-set ears, short neck, kyphoscoliosis, tighttendoachilles. Photo image taken with consent. 


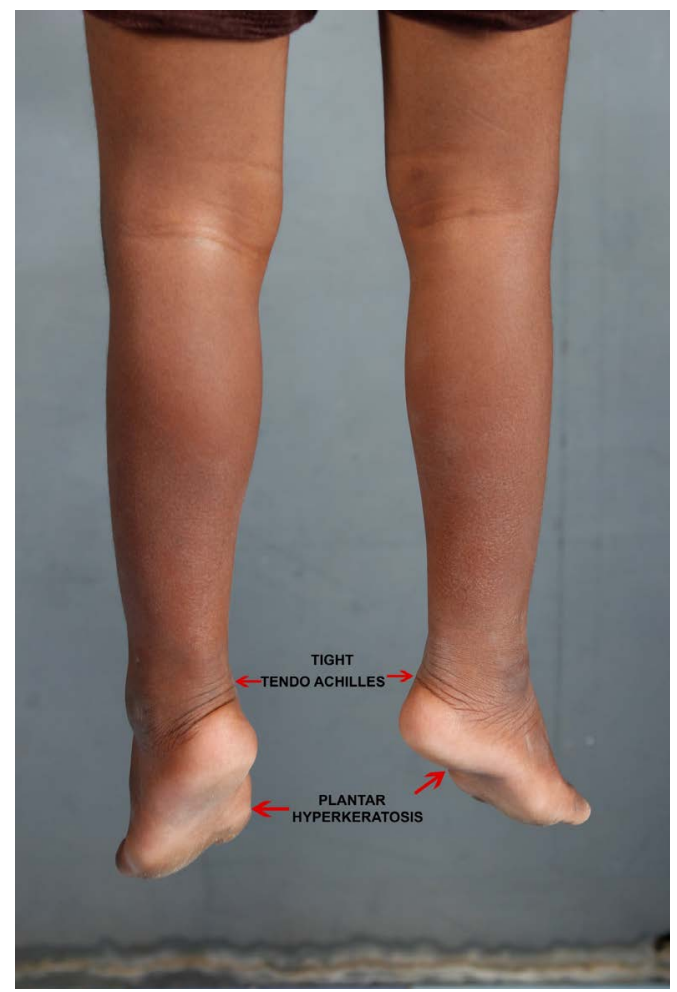

Figure 4. Showing-tight tendoachilles and plantar hyperkeratosis. Photo image taken with consent.

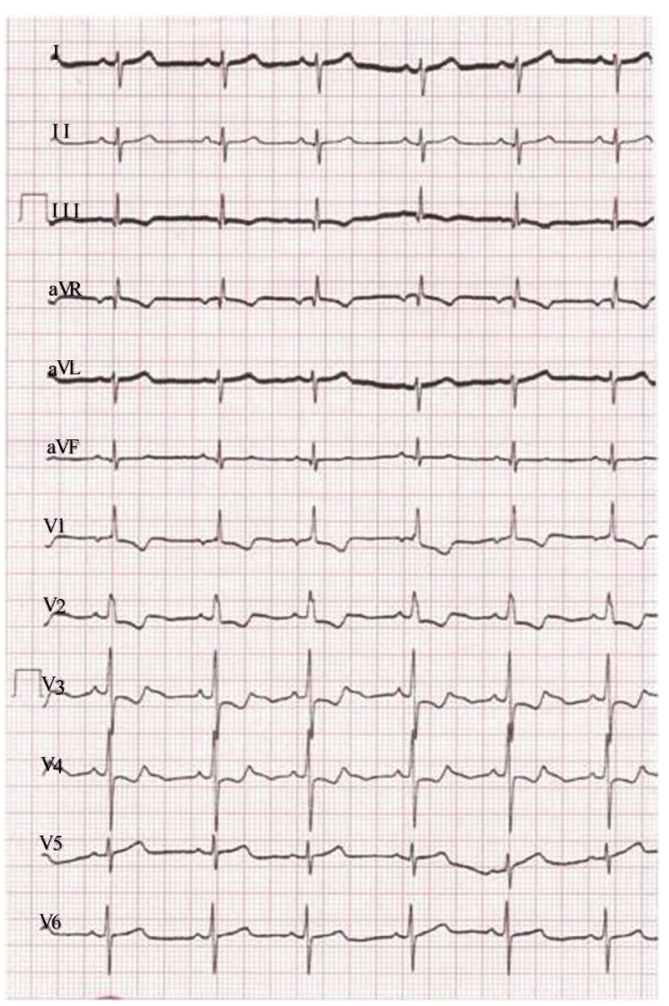

Figure 5. ECG showing RVH (right ventricular hypertrophy) $1 \mathrm{mV}=5 \mathrm{~mm}$ standardization. 


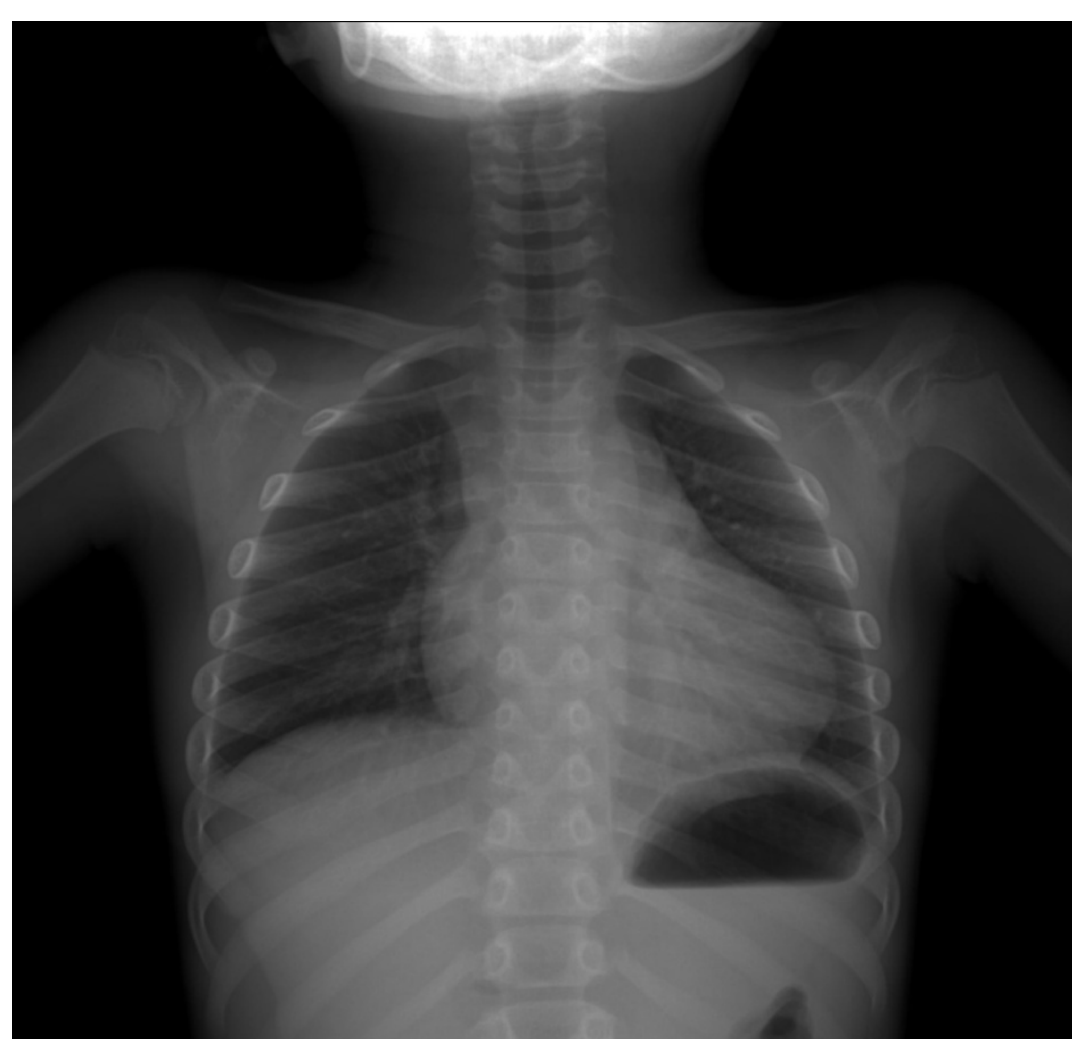

Figure 6. X-ray chest PA view showing main pulmonary artery segment dilatation and RVH (right ventricular hypertrophy). The dilated right ventricle is rounded rather than boot-shaped and its apex is above the left hemidiaphragm.

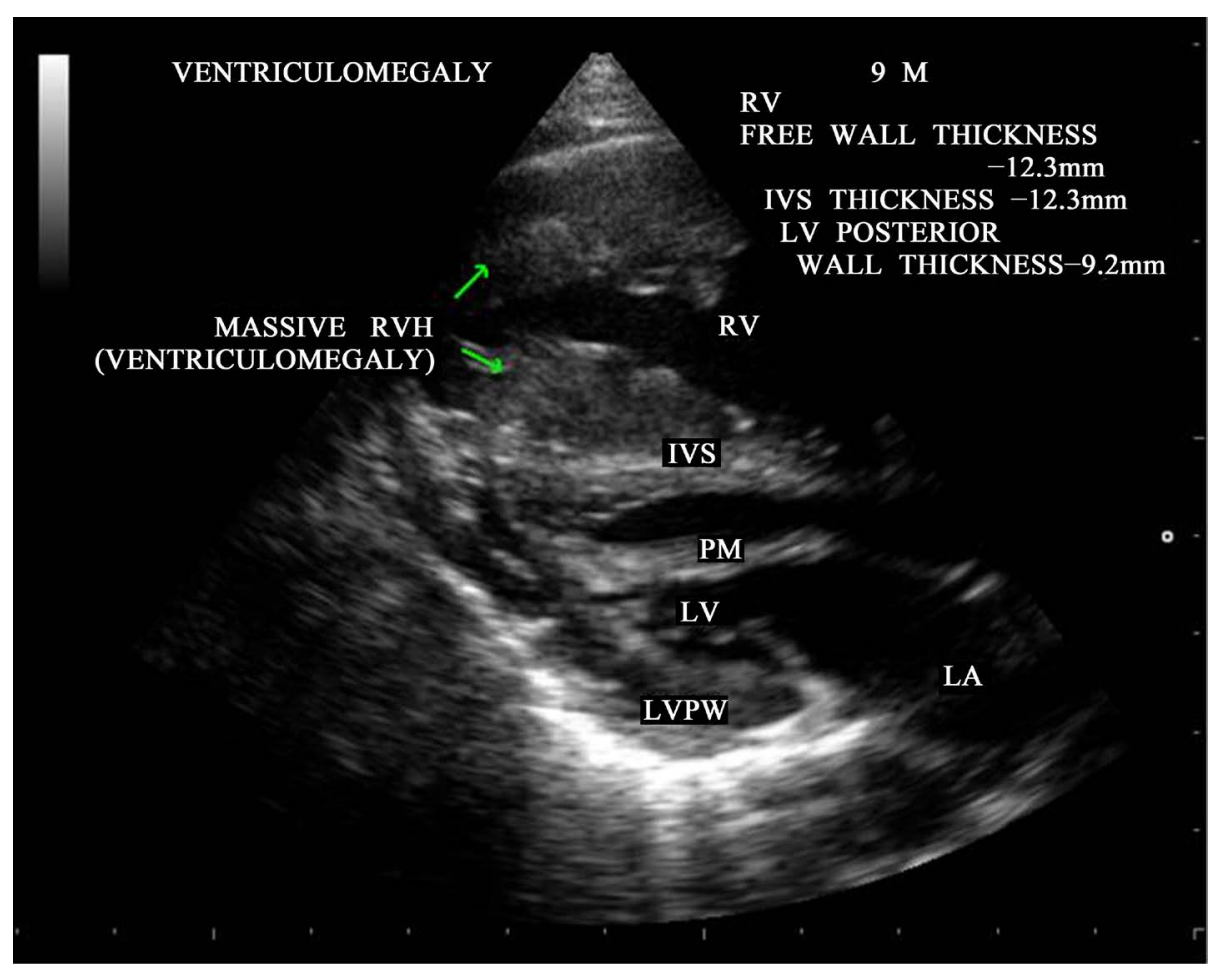

Figure 7. Showing “ventriculomegaly”-massive RVH (right ventricular hypertrophy). 


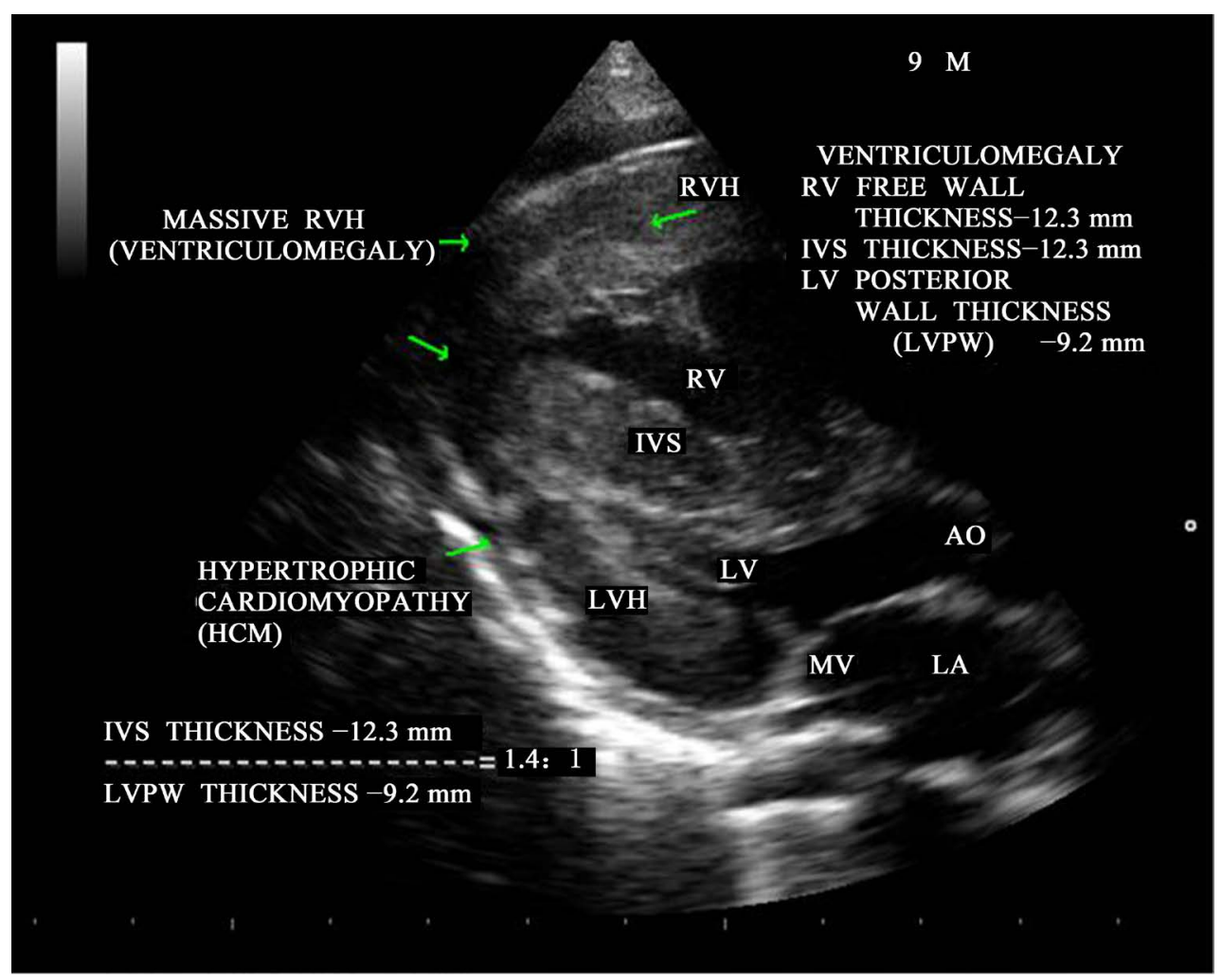

Figure 8. Parasternal long axis view showing HCM (hypertrophic cardiomyopathy).

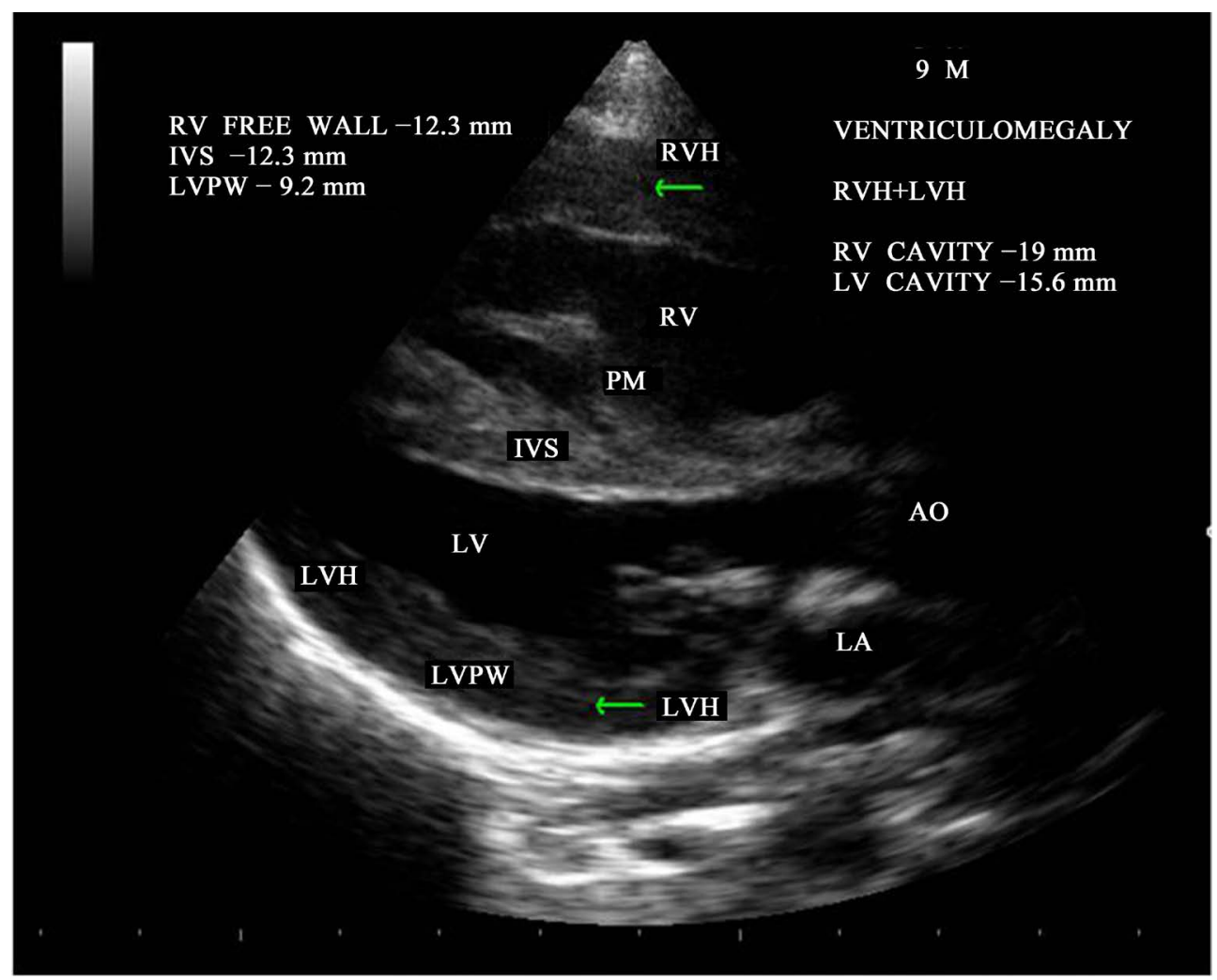

Figure 9. Parasternal long axis view showing dilated RV cavity.

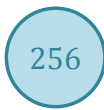




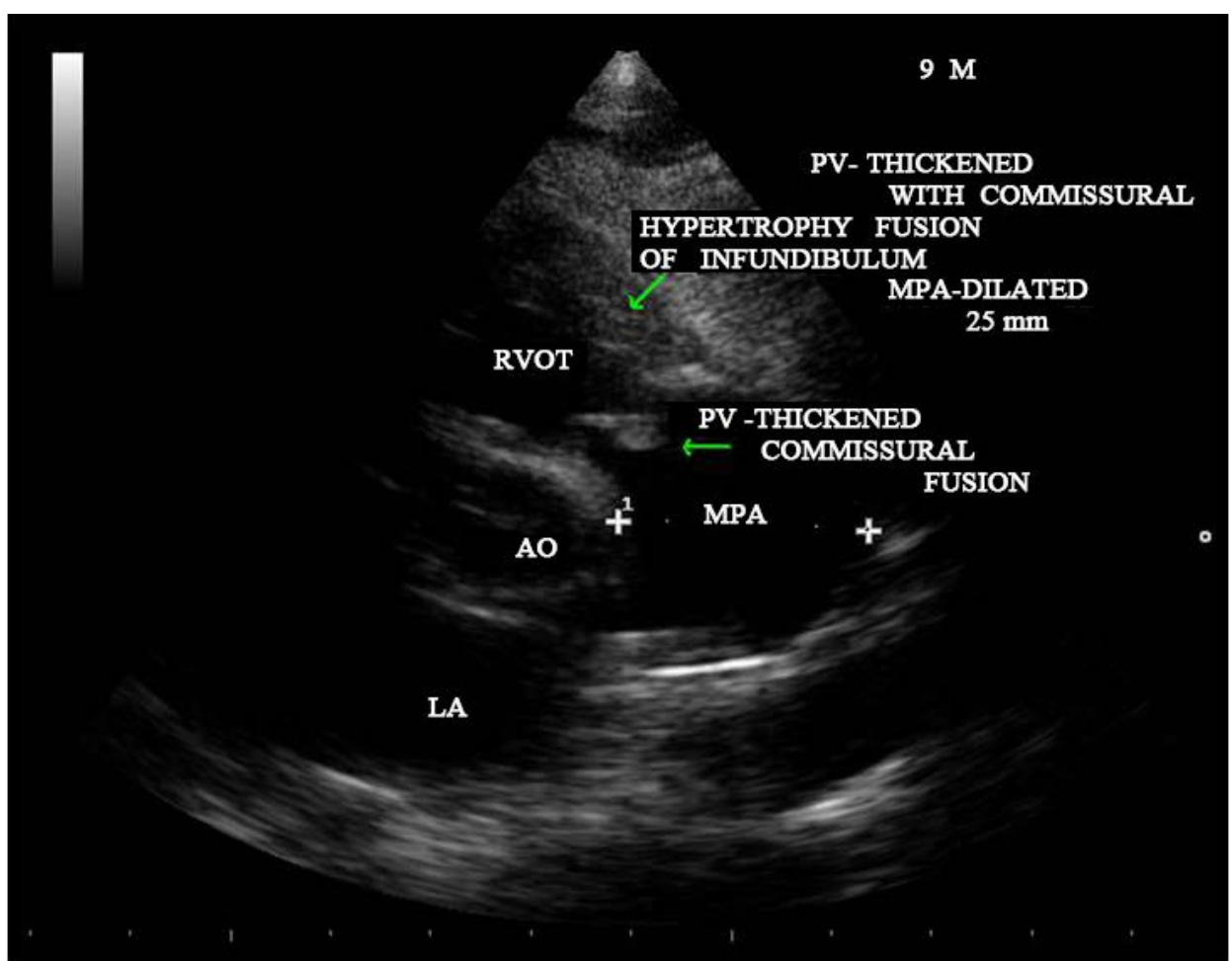

Figure 10. Showing the thickened pulmonary valve with commissural fusion and post-stenotic dilatation.

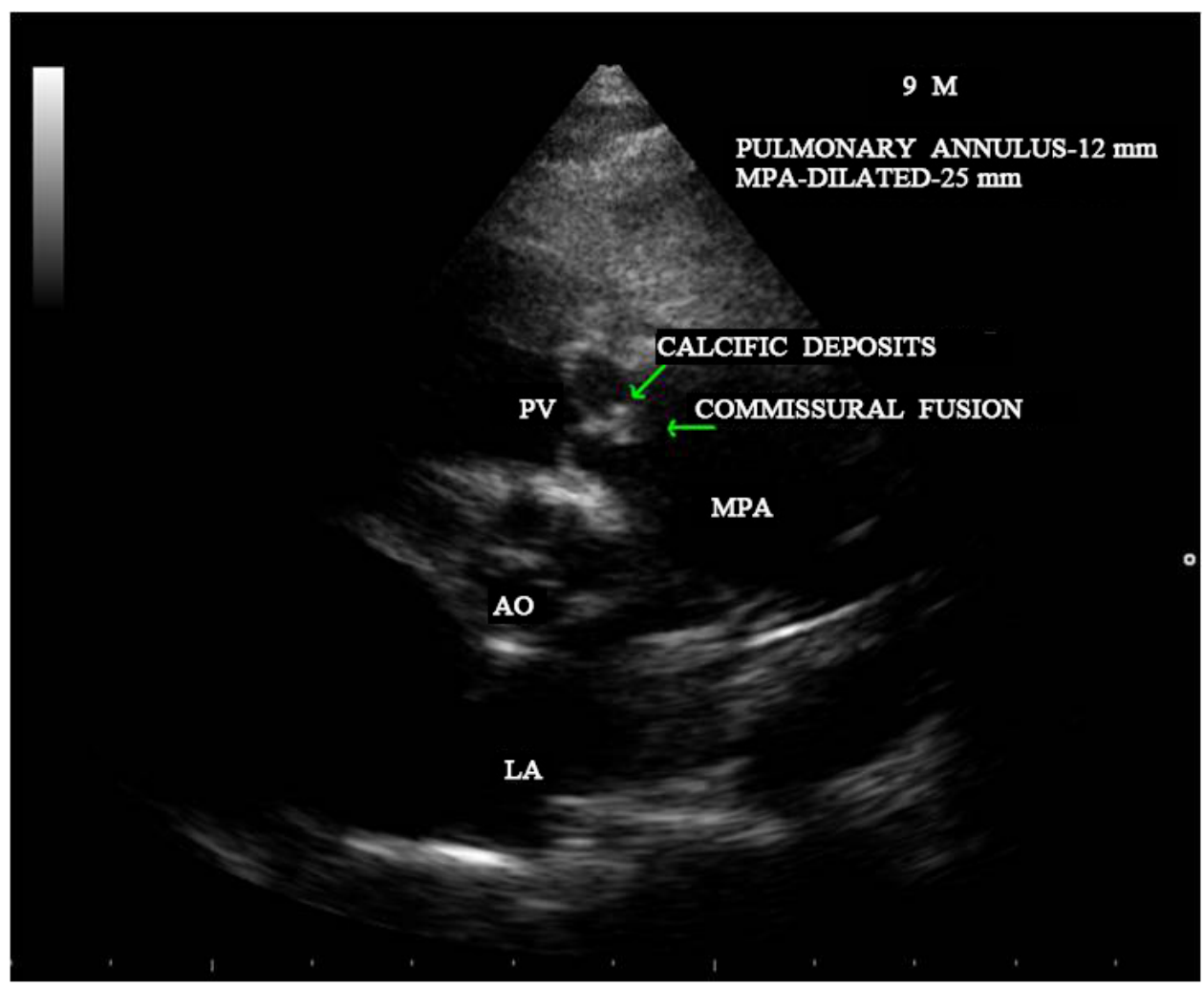

Figure 11. Short axis view showing calcific deposits on pulmonary valve-mimicking as "Lambl's excrescence". 


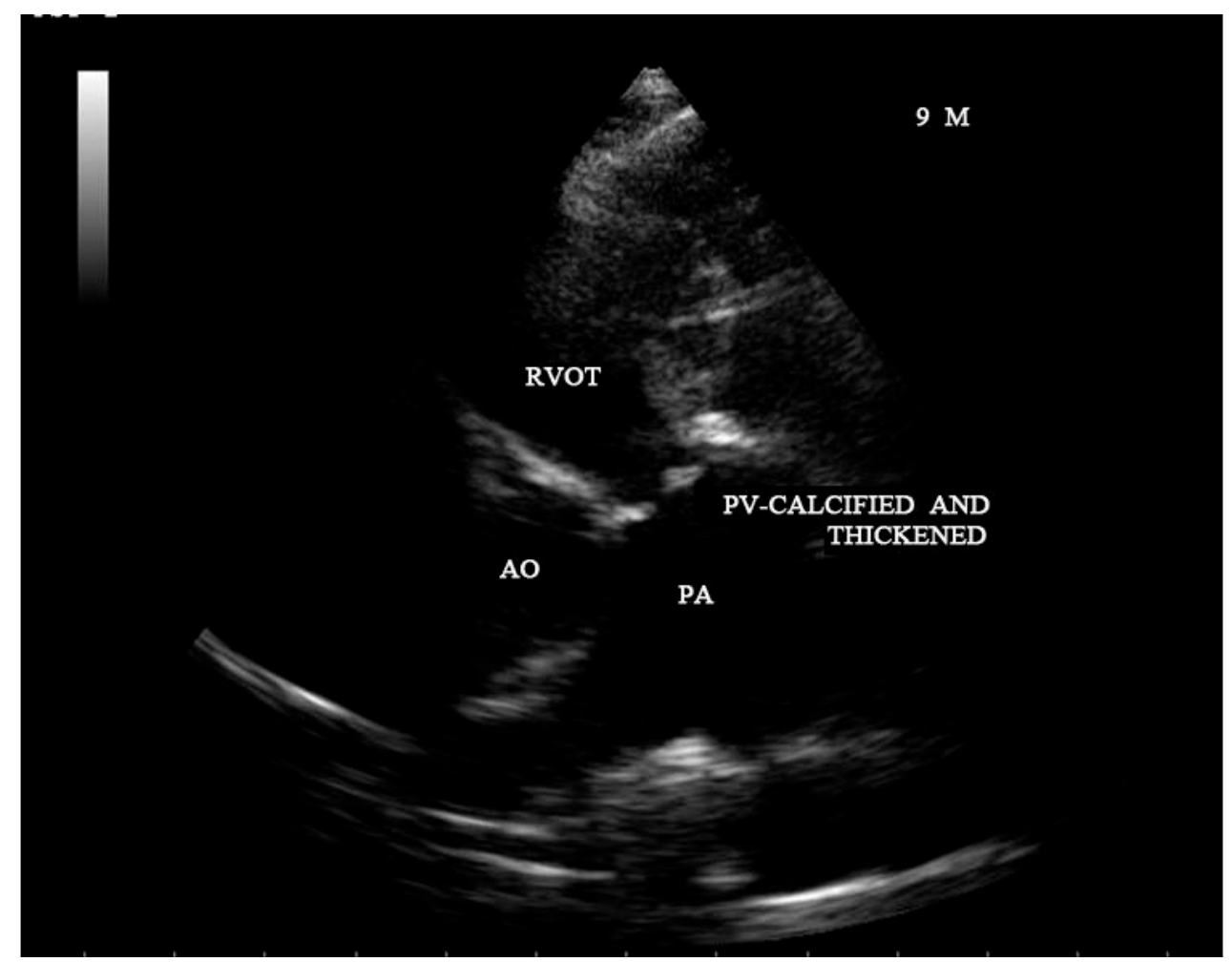

Figure 12. Showing severely thickened and calcified pulmonary valve.

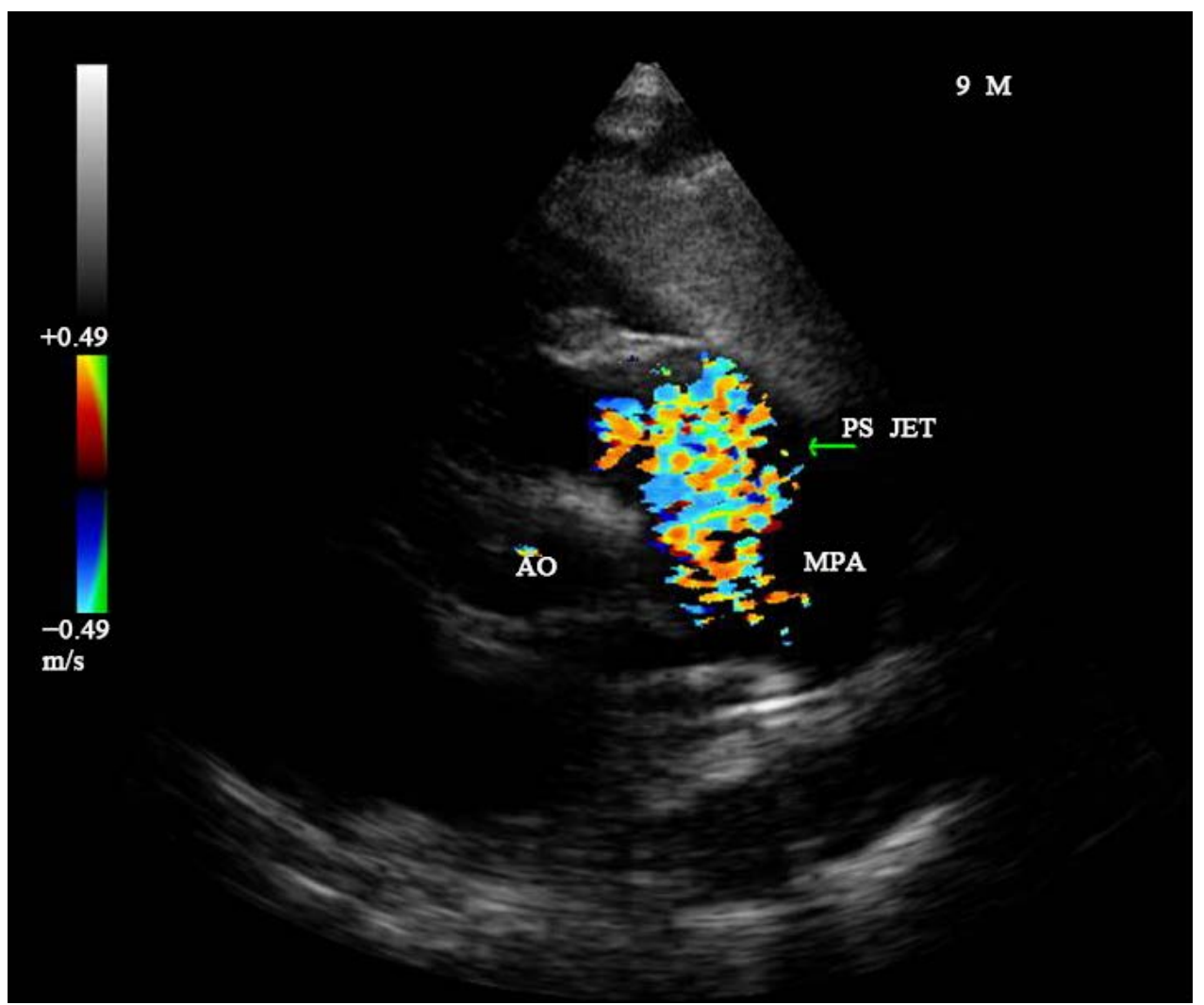

Figure 13. Showing pulmonic valve stenosis jet. 


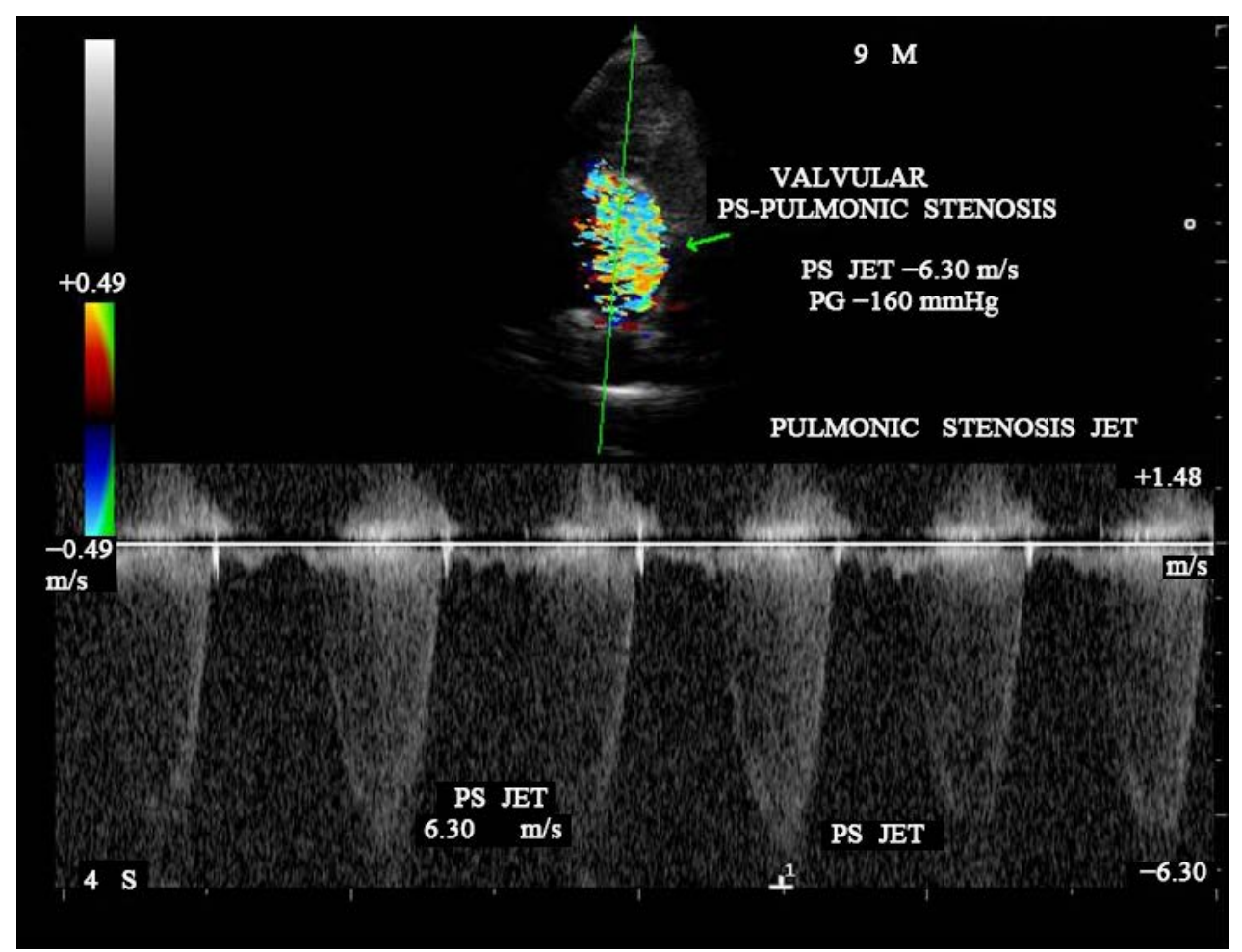

Figure 14. CW (continuous wave) doppler showing the velocity $(6.30 \mathrm{~m} / \mathrm{s})$ and gradient $(160 \mathrm{mmHg})$ of PS (pulmonary valve stenosis) jet.

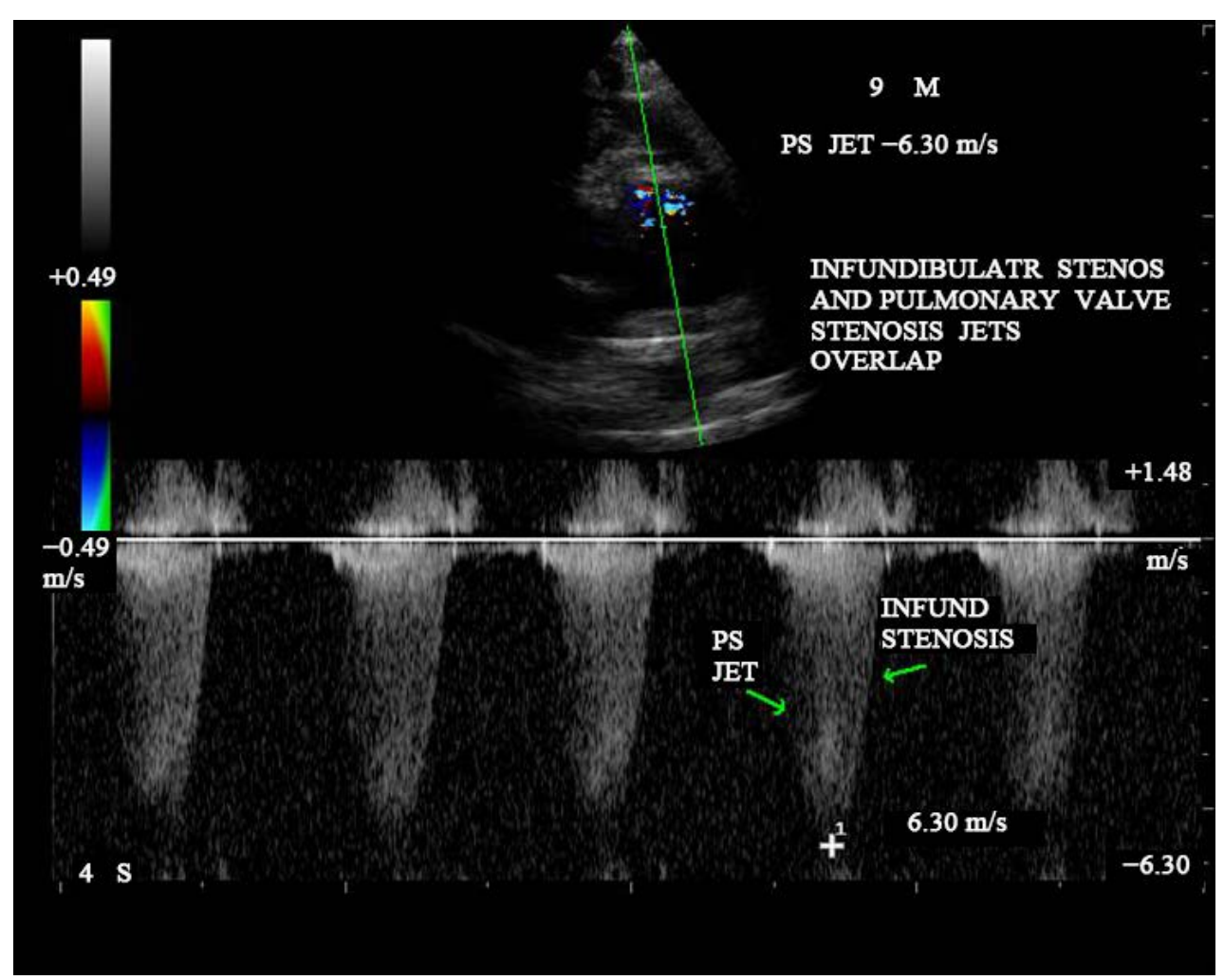

Figure 15. CW (continuous wave) doppler showing the infundibular stenosis jet (dagger-shaped) as an overlap with late systolic peaking in PS jet). 


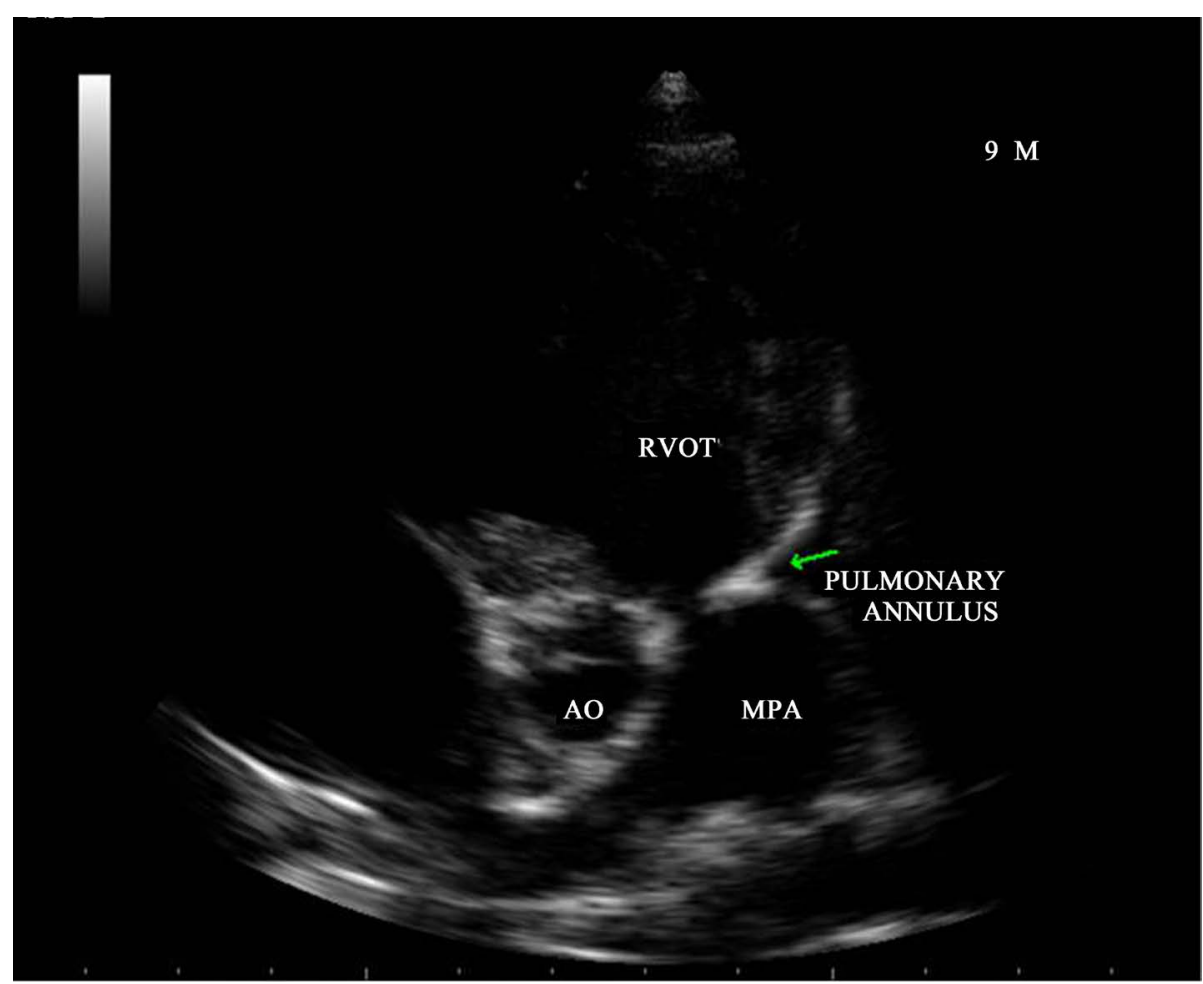

Figure 16. Inflow-outflow view showing pulmonary annulus narrowing and dilated main pulmonary artery.

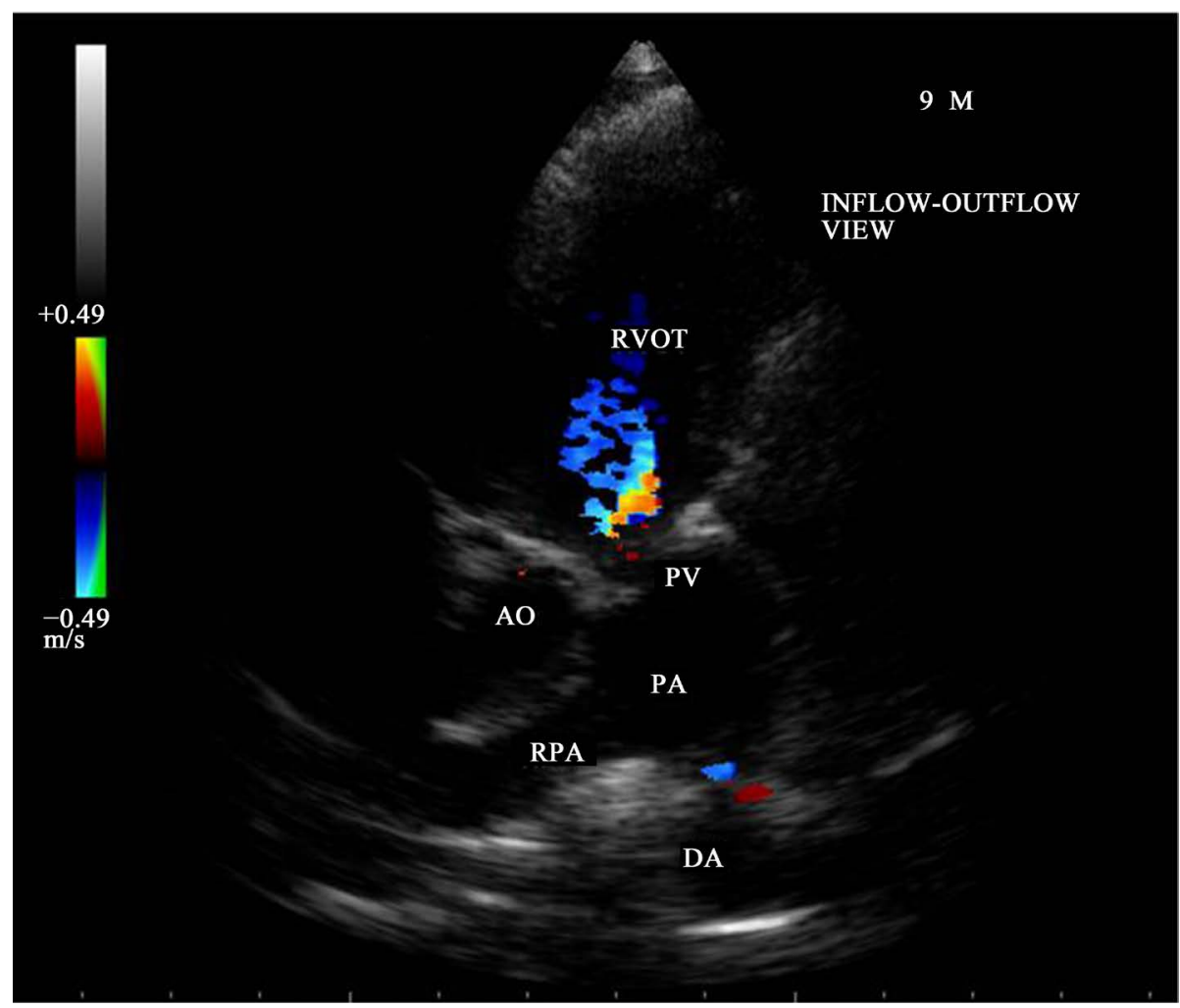

Figure 17. Inflow-outflow view showing no pulmonary regurgitation and dilated pulmonary trunk. 


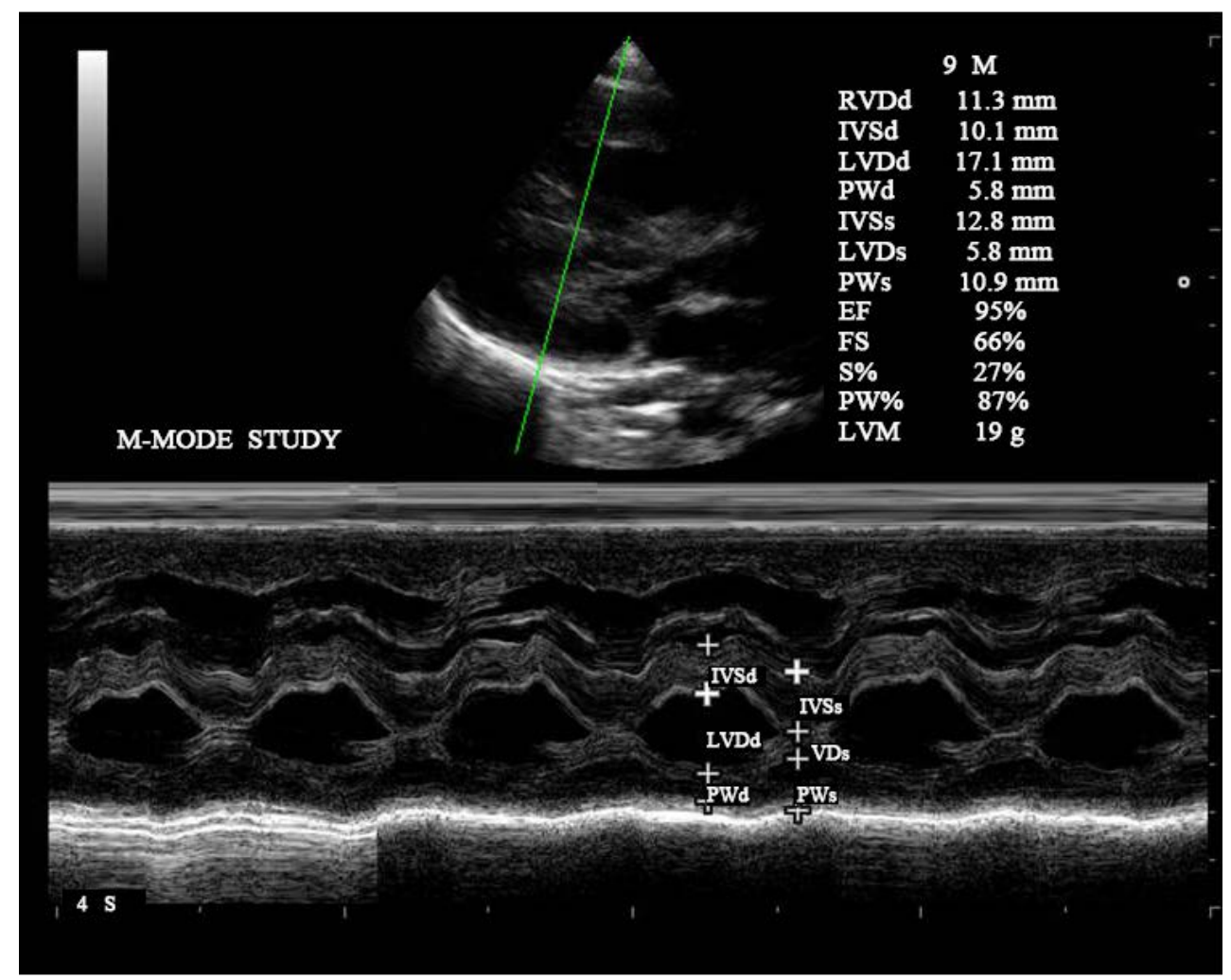

Figure 18. M-mode LV study showing high ejection fraction (EF-95\%).

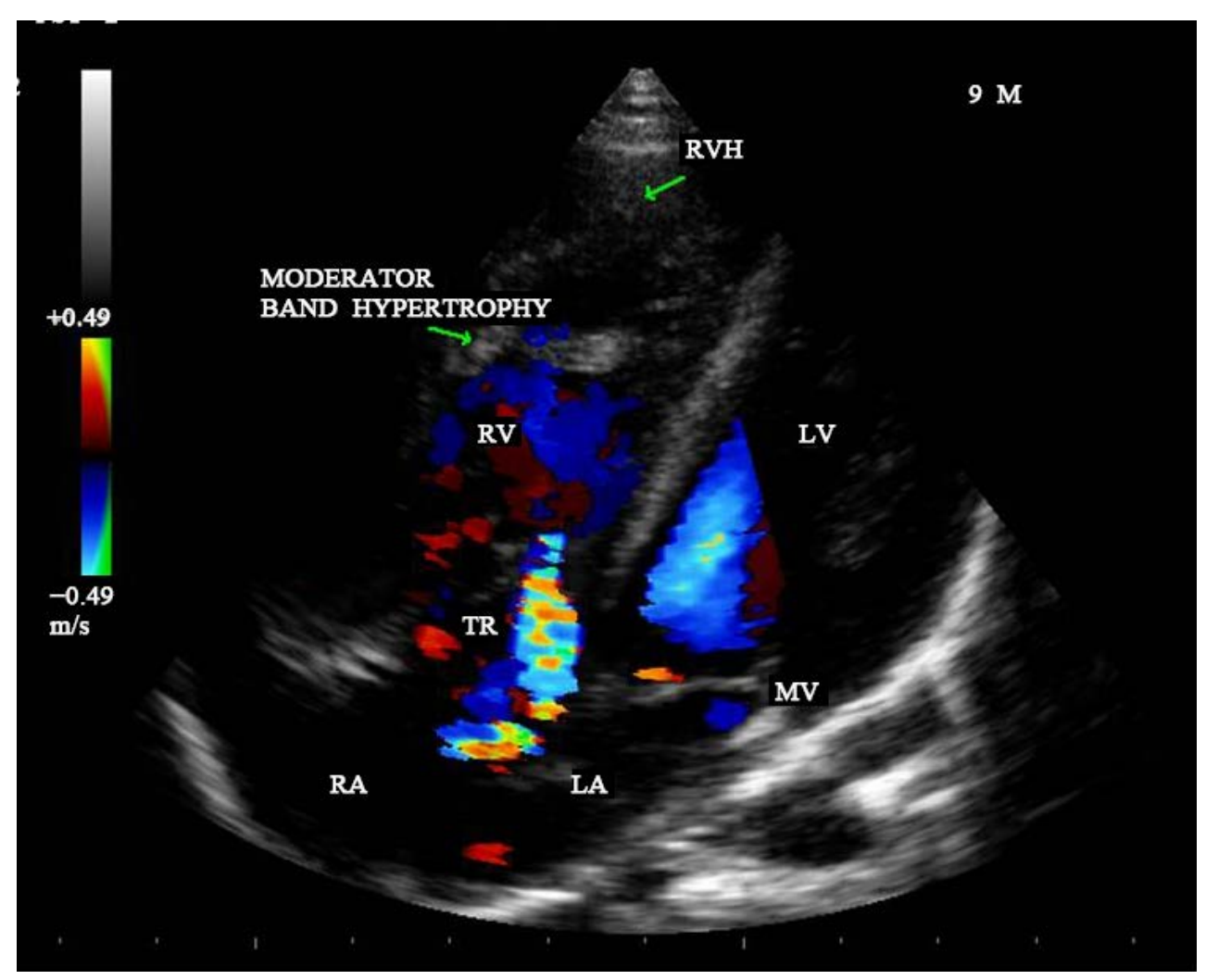

Figure 19. Showing mild to moderate tricuspid regurgitation.

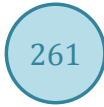




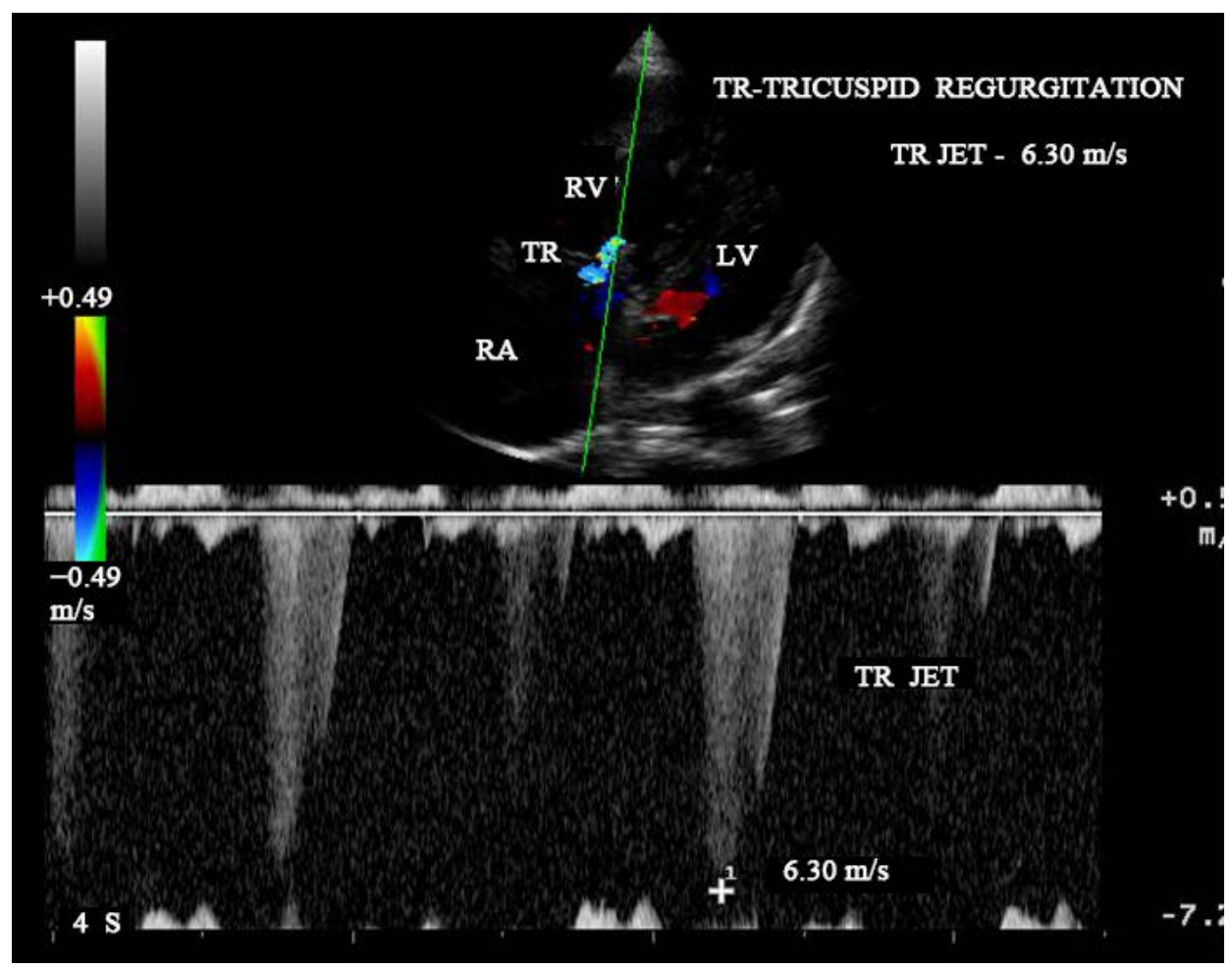

Figure 20. Apical 4 chamber view-CW doppler showing high velocity TR (tricuspid regurgitation) jet with early peaking suggesting high RV pressure at suprasystemic levels $-165 \mathrm{mmHg}$.

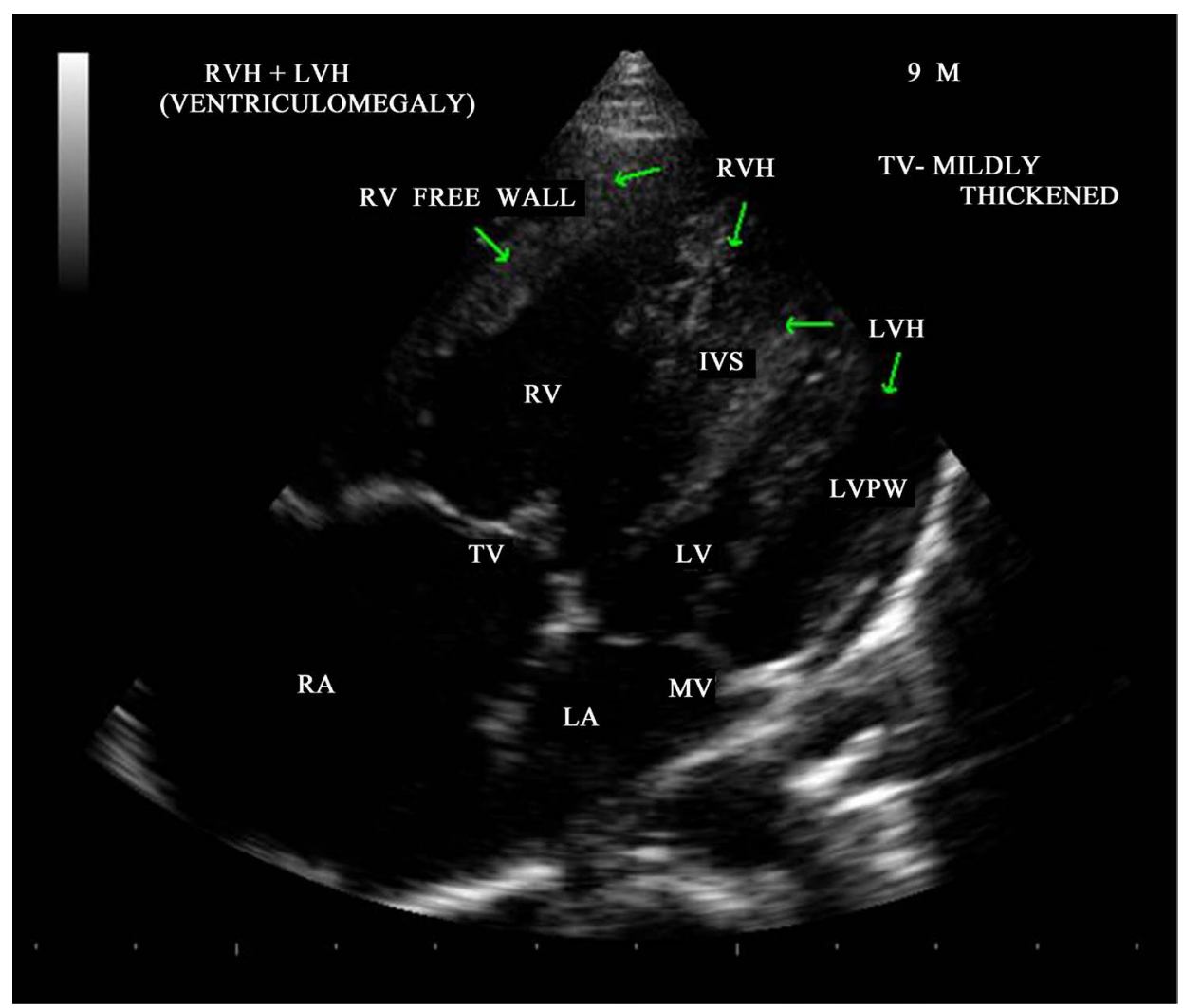

Figure 21. Showing ventriculomegaly $(\mathrm{RVH}+\mathrm{LVH})$ and dilated RA, RV. 
In the classic form of pulmonic valve stenosis, the valve is conical or dome-shaped and 2 - 4 raphes may be visible, but there is no separation into valve leaflets [12] and separate commissures cannot be identified and sometimes referred as "Functional pulmonary atresia" in neonates. The pulmonary trunk is consistently dilated because of an inherent medial abnormality that is coupled with the morphology of the mobile dome-shaped valve, not with its functional state. Less commonly, the valve may be diffusely thickened, with one, two or three leaflets and commissural fusion.

Hypertrophy of the septal and parietal bands narrowing the right ventricular infundibulum often accompanies the pulmonic valve lesion, especially if it is severe and it is dynamic in nature. The adaptive response of the right ventricle to valvular pulmonic stenosis is characterized by an increase in thickness of the free wall and the ventricular septum [13] with normal cavity size [14]. In neonates with pinpoint pulmonic stenosis, cavity size is diminished. The elevation of right ventricular pressure is accompanied by an increase in muscle mass with a concomitant increase in number of capillaries [15] in the fetus and neonate and thus, the neonatal myocardium may be better adapted to generate the high pressure necessary to overcome the severe obstruction and the increased muscle mass may enable the hypertensive ventricle to maintain a normal stroke volume than in adults in whom no change in capillary network occurs.

If the size of the stenotic orifice remains fixed, however, the degree of obstruction becomes relatively more severe as the person grows. The right ventricle eventually may dilate and fail and this process is exacerbated by the development of tricuspid insufficiency in many patients with severe pulmonic stenosis. The patient may deteriorate rapidly, cardiac output becomes inadequate at rest, leads to right ventricular failure, which is the most common cause of death [16].

Normal birth weight, growth and development are characteristic of mobile dome-shaped pulmonic valve stenosis and experience little or no difficulty in infancy and childhood [17]. Neonates with pinpoint pulmonic valve stenosis confront rapidly progressive condition further and early death.

\section{Critical Pulmonic Stenosis}

In utero, when the valvular pulmonic stenosis is severe, right ventricular output decreases and a large right-toleft shunt is established at atrial level and this condition has been termed as "critical pulmonic stenosis" [18]. Right ventricle is hypoplastic due to excessive hypertrophy and affected infants are cyanotic at birth with systemic or supra-systemic right ventricular pressures and the cyanosis persists for months after the stenosis is relieved until the hypertrophy decreases with an increase in right ventricular size.

It is surprising that an appreciable number of patients with moderate to severe pulmonic stenosis are asymptomatic. Patients with right ventricular systolic pressures between 50 and $100 \mathrm{mmHg}$ include New Zealand longdistance runner and an English hockey captain [19]. A 17-year-old boy who played baseball despite a right ventricular systolic pressure of nearly $200 \mathrm{mmHg}$, and a woman who worked full-time with a right ventricular pressure of nearly $200 \mathrm{mmHg}$ and died at the age of 60 years [20]. In Costello syndrome, the valvular pulmonic stenosis is usually non-progressive and found in $44 \%$ of cases and hypertrophic cardiomyopathy is chronic or progressive and found in $61 \%$ of cases and atrial septal defect was uncommon [21].

Calcific deposits are rare in congenital stenotic pulmonic valves and thickening of tricuspid valve may be present, and the valve may become regurgitant. The right atrium may be thick and dilated as a result of the increased pressure necessary to fill the hypertrophic right ventricle.

The most common cause of acquired valvular pulmonic stenosis is carcinoid heart disease. Interestingly, calcification of affected valve is rare and may be considered a notable negative echocardiographic feature of carcinoid heart disease [22] and lack of commissural fusion [23].

The etiological differential features of valvular pulmonic stenosis are shown in Table 1.

\subsection{Clinical Characteristics}

\subsubsection{General Features}

Individuals with Costello syndrome have characteristic craniofacial, musculoskeletal, cutaneous and cardiac abnormalities. Features include relative macrocephaly (abnormally large head), coarse facial feature such as epicanthal folds, full cheeks, low-set ears as shown in Figure 3 and wide nostrils. Musculoskeletal features include reduced range of mobility of shoulder and elbows, kyphoscoliosis as shown in Figure 3, short stature as shown in Figure 2 and hip dysplasia. Skin may lack elasticity, wrinkled, thickened skin (plantar hyperkeratosis as shown in Figure 4 thickening of stratum corneum, the outermost layer of epidermis in sole, usually contains 
Table 1. Etiological features of valvular pulmonic stenosis.

Congenital

Cusps are mobile or fixed, dysplastic

Valvular regurgitation is uncommon

Calcific deposits little. Occasionally dense. or remain asymptomatic

Right ventricular free wall, septal and infundibular hypertrophy severe

High right ventricular systolic pressures with suprasystemic levels frequent

Isolated or associated with other congenital heart defects

Pin-point valvular stenosis is usually progressive. Ventricular hypertrophy get regress after valvuloplasty or valve replacement with bioprostheses if calcific

Rheumatic

Carcinoid

After birth

Mostly mobile

Frequent

Mostly symptomatic with history of febrile episodes and joint pains during childhood

Less severe

Suprasystemic level is uncommon

May affect all four valves

May regress with treatment. Need valvuloplasty or valve replacement. (Bioprostheses for right-sided lesions and mechanical valves for left -sided lesions)
No calcification, bright fibrous plaques on endocardial surface of cardiac chambers and valves (composed of smooth muscle cells embedded in acid mucopolysaccharide rich matrix with sparse of collagen fibers and lack of elastic fibers)

Symptomatic with episodic cutaneous flushing, prolonged diarrhea lepisodes, bronchospasm and labile hypertension

Hypertrophy is Uncommon, whitish right ventricular endocardial fibrous plaques present

Right ventricular pressures are not much increased

Usually right sided valves and occasionally all four valves (primary or metastatic lung carcinoid) affected and may require quadruple valve replacement (mechanical valves preferable for both sides)

Symptoms may respond to somatostatinanaloges (octreotide, lanreotide). Oral ketanserin for hypertensive crisis and intravenous octreotide to control hypotension.

increased amount of the protective protein, keratin and associated with an increase in granular layer) and unusual tightening of the fibrous cords on the back of the heels (Achilles tendon) as shown in Figure 3 and Figure 4. Cardiovascular manifestations include ventriculomegaly, valvular pulmonic stenosis, hypertrophic cardiomyopathy and atrial arrhythmias occasionally.

This child is having typical features of large head, skin folding below the lower eyelids as shown in Figure 1, 
low set ears as shown in Figure 3, teeth abnormalities as shown in Figure 1 and Figure 2, short stature as shown in Figure 2, ulnar deviation of forearm and cardiac manifestations of ventriculomegaly, valvular pulmonic stenosis, hypertrophic cardiomyopathy as in Figures 7-21 and warm sociable personalities as shown in Figure 1, suggesting the Costello syndrome.

Cardiac examination showed prominent systolic murmur over precordium, with ECG and X-ray features of Right ventricular hypertrophy as shown in Figure 5 and Figure 6 are consistent with severe valvular pulmonic stenosis. ECG based R wave height in $\mathrm{V}_{1} \times 5$ to predict RV systolic pressure $(17 \times 5=70 \mathrm{mmHg})$ in this case is not correlated with echocardiographic RV (right ventricular) systolic pressure measurements (165 mmHg) and it may be due to chest wall deformity of kyphoscoliosis as shown in Figure 3. Interestingly, TR (tricuspid regurgitation) jet velocity $(6.30 \mathrm{~m} / \mathrm{s})$ correlates with PS (pulmonic valve stenosis) jet velocity of $6.30 \mathrm{~m} / \mathrm{s}$ as shown in Figure 14, Figure 15 and Figure 20.

\subsubsection{Echocardiographic Features}

Transthoracic echocardiographic images revealed a thickened, calcified, bicuspid pulmonic valve with commissural fusion in 2D imaging as shown in Figures 10-12. Color Doppler evaluation showed severe valvular pulmonic stenosis as in Figure 13 and Figure 14 and no pulmonary regurgitation as shown in Figure 17. Continuous wave (CW) Doppler imaging revealed a high velocity valvular pulmonic stenosis jet (6.30 m/s) with a peak gradient of $160 \mathrm{mmHg}$ as in Figure 14 and an overlap jet due to infundibular stenosis with a late systolic peaking (dagger-shaped) as in Figure 15. Apical 4 chamber view revealed mild to moderate tricuspid regurgitation as in Figure 19 with a high velocity jet of $6.30 \mathrm{~m} / \mathrm{s}$ as in Figure 20 due to increased right ventricular (RV) systolic pressure and a peak gradient of $160 \mathrm{mmHg}\left(4 \mathrm{~V}^{2}-4 \times 6.30^{2}=160 \mathrm{mmHg}\right)$ with an estimated RV systolic pressure of $165 \mathrm{mmHg}\left(4 \mathrm{~V}^{2}+\mathrm{RA}\right.$ pressure assumed as $5 \mathrm{mmHg}$ since JVP (Jugular venous pressure) is not elevated). Inflow-outflow views revealed poststenotic dilatation of main pulmonary artery segment (25 mm) as in Figure 10, Figure 12, Figure 16 and Figure 17. Parasternal long axis view revealed ventriculomegaly as massive hypertrophy of right ventricle, hypertrophy of left ventricle with features of hypertrophic cardiomyopathy as in Figure 7 and Figure 8 and a dilated RV cavity as in Figure 9 rather than hypoplastic.

\subsection{Treatment}

Costello syndrome is a "RASopathy", characterized by increased growth at the prenatal stage, growth deficiency at postnatal stage with unique cardiovascular features of valvular pulmonic stenosis and hypertrophic cardiomyopathy. Animal models showed G12V mutation may also cause Costello syndrome and it does not appear to develop tumors as reported by Spanish researchers [24], Italian and Japanese researchers [25].

\subsubsection{Specific Treatment}

Treatment is directed towards the specific symptoms that are apparent in each individual. Bracing and physiotherapy may be used to treat skeletal abnormalities and surgery may be required to lengthen the tight tendoachilles. Cardiac abnormlities such as hypertrophic cardiomyopathy may be treated with beta-blockers or calcium channel blockers. Balloon valvuloplasty or surgical valve replacement may be utilized to relieve the stenotic obstruction of the pulmonary valve.

\subsubsection{Investigational Treatment}

Farnesyl transferase inhibitor (FTI) affects H-Ras as suggested by Francis Collins at American Society of Human Genetic Meeting in 2005 and Mark Kieras agreed this in 2007 at $1^{\text {st }}$ International Costello Syndrome Research Symposium.

Another medication that affects H-Ras is Lovastatin which helps in children of Costello syndrome with cognition as reported by Alcino Silva in 2007.

MEK (mitogen-actvated ERK kinase) inhibitors such as cobimetinib, relumetinib and trametinib, Raf inhibitors such as sorafenib, encorafenib, dabrafenib and vemurafenib [26] also helps to inhibit the pathway closer to the cell nucleus in Costello syndrome.

Congenital stenotic pulmonic valve rarely contains calcific deposits. Covambias and colleagues [27] reported calcific pulmonic stenosis in a 56-year-old man in whom the isolated stenotic lesion was treated by valve replacement with a bioprosthetic valve.

The valvular pulmonic stenosis is rarely progressive in Costello syndrome and the child was advised periodic 
follow-up. Since the stenotic pulmonic valve contains moderate calcification, this child may need valve replacement (bioprostheses) if any symptoms occur on follow up, rather than balloon valvuloplasty. The skeletal abnormalities were not affecting the normal activities and so bracing or physiotherapy was not advised. There are no obstructive manifestations such as syncopal episodes due to hypertrophic cardiomyopathy in this child, beta-blockers or calcium channel blockers were also not advised at this moment.

\section{Conclusion}

Reported estimate of Costello syndrome prevalence ranges from 1 in 300,000 to 1 in 1.25 million people [28]. This genetically inherited RASopathy with features of valvular pulmonic stenosis and ventriculomegaly and not associated with tumors or neurological lesions was found by Transthoracic 2D echocardiographic imaging in a 9-year-old male boy in 2016 at this hospital in India.

\section{References}

[1] Costello, J.M. (1977) A New Syndrome; Mental Subnormality And Nasal Papillomata. Australlian Paediatric Journal, 13, 114-118. http://dx.doi.org/10.1111/j.1440-1754.1977.tb01135.x

[2] Aoki, Y., Niihori, T., Kawame, H., Kurosawa, K., Ohashi, H., Tanaka, Y., Filocamo, M., Kato, K., Suzuki, Y., Kure, S. and Matsubara, Y. (2005) Germline Mutations in HRAS Proto-Oncogene Cause Costello Syndrome. Nature Genetics, 37, 1038-1040. http://dx.doi.org/10.1038/ng1641

[3] Morgagni, J.B. (1761) De Sedibus et Causis Morborum. (The Seats and Causes of Diseases) Volume 1, Venice, Remondini, 154.

[4] Hofman, J.E. and Christianson, R. (1978) Congenital Heart Disease in a Cohort of 19,502 Births with Long Term Follow-Up. American Journal of Cardiology, 42, 641-645. http://dx.doi.org/10.1016/0002-9149(78)90635-5

[5] Waller, B.F. (1984) Morphological Aspects of Valvular Heart Disease, Part-1. Current Problems in Cardiology, 9, 166.

[6] Gikonyo, B.M., Lucas, R.V. and Edwards, J.E. (1987) Anatomic Features of Congenital Pulmonary Valvar Stenosis. Pediatric Cardiology, 8, 109-116. http://dx.doi.org/10.1007/BF02079465

[7] Altrichter, P.M., Olson, I.J., Edwards, W., D., Ruga, J.F. and Danielson, G.K. (1989) Surgical Pathology of the Pulmonic Valve. A Study of 116 Cases Spanning 15 Years. Mayo Clinic Proceedings, 64, 1352-1360. http://dx.doi.org/10.1016/S0025-6196(12)65377-4

[8] Hurwitz, L.E. and Roberts, W.C. (1973) Quadricuspid Semilunar Valve. American Journal of Cardiology, 31, 623-626. http://dx.doi.org/10.1016/0002-9149(73)90332-9

[9] Keith, A. (1909) The Hunterian Lectures on Malformations of the Heart. Lancet, 2, 359.

[10] Moore, G.W., Hutchins, G.M., Brito, J.C., et al. (1980) Congenital Malformations of the Semilunar Valves. Human Pathology, 11, 367-372. http://dx.doi.org/10.1016/S0046-8177(80)80033-5

[11] Oka, M. and Angrist, G.M. (1967) Mechanism of Cardiac Valvular Fusion and Stenosis. American Heart Journal, 74, 37-47. http://dx.doi.org/10.1016/0002-8703(67)90038-5

[12] Edwards, J.E., Gould, S.E. and Thomas C.C. (1953) Congenital Malformations of the Heart and Great Vessels, Pathology of the Heart, Springfield II. 656-705.

[13] Perloff, J.K. (1991) The Increase and Regression of Ventricular Mass. In: Perloff, J.K. and Child, J.S, Eds., Congenital Heart Disease in Adults, W.B. Saunders, Philadelphia.

[14] Nakazawa, M., Marks, R.A., Isabel-Jones, J. and Jarmakani, J.M. (1976) Right and Left Ventricular Volume Characteristics in Children with Pulmonary Stenosis and Intact Ventricular Septum. Circulation, 53, 884. http://dx.doi.org/10.1161/01.CIR.53.5.884

[15] Rudolph, A.M. (1974) Congenital Diseases of the Heart. Yearbook Medical, Chicago.

[16] Geraci, J.E., Burchell, H.B. and Edwards, J.E. (1953) Cardiac Clinics, CXL. Congenital Pulmonary Stenosis with Intact Ventricular Septum in Persons More than 50 Years of Age. Report of Two Cases. Proceedings of Staff Meetings of the Mayo Clinic, 28, 346.

[17] Hayes, C.J., Gersony, W.M., Driscoll, D.J., et al. (1993) Second Natural History Study of Congenital Heart Defects. Results of Treatment of Patients with Pulmonary Valvar Stenosis. Circulation, 87, 128-137.

[18] Freed, M.D., Rosenthal, A.R., Bernhard, W.F., et al. (1973) Critical Pulmonary Stenosis With Diminutive Right Ventricle in Neonates. Circulation, 48, 875-882. http://dx.doi.org/10.1161/01.CIR.48.4.875

[19] Perloff, J.K. (2003) Clinical Recognition of Congenital Heart Disease. 5th Edition, Chapter 11, Saunders, Philadelphia, 
168.

[20] Perloff, J.K. (1979) Postpediatric Congenital Heart Disease. Natural Survival Pattern, Cardiovascular Clinics, 10, 2738.

[21] Lin, A.E., et al. (2011) Clinical, Pathological, and Molecular Analysis of Cardiovascular Abnormalities in Costello Syndrome: A Ras/MAPK Pathway Syndrome. American Journal of Medical Genetics Part A, 155, 486-507. http://dx.doi.org/10.1002/ajmg.a.33857

[22] Fox, D.J. and Khattar, R.S. (2004) Carcinoid Heart Disease: Presentation, Diagnosis, and Management. Heart, 90, 1224-1228. http://dx.doi.org/10.1136/hrt.2004.040329

[23] Lancellotti, P., Tribouilloy, C., Hagendorff, A., Bogdan, A., Thor Edvardsen, P., Pierard, L.A., Badano, L. and Zamorano, J.L. (2013) Recommendations for the Echocardiographic Assessment of Native Valvular Regurgitation. An Executive Summary from the European Association of Cardiovascular Imaging. European Heart Journal—Cardiovascular Imaging, 14, 611-644. http://dx.doi.org/10.1093/ehjci/jet105

[24] Schuhmacher, A., Guerra, C., Sauzeau, V., Canamero, M., Bustelo, X. and Barbacid, M. (2008) A Mouse Model for Costello Syndrome Reveals an Angiotensin-II Mediated Hypertensive Condition. The Journal of Clinical Investigation, 118, 2169-2179.

[25] Santoriello, C., Deflorian, G., Pezzimenti, F., Kawakami, K., Lanfrancone, L., D’adda Di Fagagna, F. and Mione, M. (2009) Expression of H-RAS V12 in a Zebrafish Model of Costello Syndrome Causes Cellular Senescence in Adult Proliferating Cells. Disease Models \& Mechanisms, 2, 56-67. http://dx.doi.org/10.1242/dmm.001016

[26] Wong, K.-K. (2009) Recent Developments on Anti-Cancer Agents Targeting the Ras/Raf/MEK/ERK Pathway. Recent Patents on Anti-Cancer Drug Discovery, 4, 28-35. http://dx.doi.org/10.2174/157489209787002461

[27] Covarrubias, E.A., Sheikh, M.U., Isner, J.I., Gomes, M., Hufnagel, C.A. and Roberts, W.C. (1979) Calcific Pulmonic stEnosis in Adulthood: Treatment by Valve Replacement (Porcine Xenograft) with Postoperative Hemodynamic Evaluation. Chest, 75, 399-402. http://dx.doi.org/10.1378/chest.75.3.399

[28] Costello Syndrome (2016) Genetics Home Reference. United States National Library of Medicine.

\section{Submit or recommend next manuscript to SCIRP and we will provide best service for you:}

Accepting pre-submission inquiries through Email, Facebook, LinkedIn, Twitter, etc.

A wide selection of journals (inclusive of 9 subjects, more than 200 journals)

Providing 24-hour high-quality service

User-friendly online submission system

Fair and swift peer-review system

Efficient typesetting and proofreading procedure

Display of the result of downloads and visits, as well as the number of cited articles

Maximum dissemination of your research work

Submit your manuscript at: http://papersubmission.scirp.org/ 